\title{
Design of a Control System for Active and Reactive Power Control of a Small Grid- Connected Wind Turbine
}

\author{
Md. Alimuzzaman ${ }^{1}$, M. T. Iqbal ${ }^{2}$ \\ Faculty of Engineering and Applied Science, Memorial University of Newfoundland \\ St. John's, NL, Canada, A1B 3X5 \\ ${ }^{1}$ ma6762@mun.ca; ${ }^{2}$ tariq@mun.ca
}

\begin{abstract}
Reactive power flow between a wind turbine system and the grid is an important issue especially when the wind turbine is connected to a remote grid. In this research, a control system has been developed that allows wind turbine to provide reactive power to the local load connected between the grid and the wind turbine. The supplied reactive power from the wind turbine is controlled by changing the phase angle of Pulse Width Modulation (PWM) in the wind turbine inverter. A proportional controller is used to maintain the reactive power supplied by the wind turbine. Another PI controller is used to maintain the wind turbine operation at an optimum tip speed ratio (TSR) to extract maximum power from the wind. The proposed system along with all sub-systems has been modelled and simulated in Matlab/ Simulink. The simulation results confirm that the designed system is able to control the wind turbine and capable of providing the required reactive power. Results show that the designed system is able to maintain the system power factor close to unity for a range of wind speeds.
\end{abstract}

\section{Keywords}

Reactive Power Control; Small Wind Turbine Control; Small Grid-connected wind Turbine; Renewable Energy

\section{Introduction}

Wind turbine generation has been contributing to a remarkable percentage to the total power generation in the world. Recently, it has been increasing dramatically because of governments support and public environmental concerns (Cultura 2011). According to British petroleum statistical review of world energy June, 2012, worldwide wind energy production has increased by more than $25.8 \%$ in 2011 from 2010. Wind power has contributed to about 194.8 million tonnes oil equivalent energy in 2011 (BP 2012).

Small wind turbines are becoming popular, mainly used to meet small community energy demand, water pumping and for remote power generation. Grid- connected small wind turbines are very useful where both the grid and the wind energy are available. If the wind turbine is grid-connected, it can use the grid to store excess power and user can get power from grid when there is a lack of power production from the wind. Wind turbine power production depends on wind speed. The output power is not constant at all as wind speed changes all times. Wind turbine can extract maximum power when the rotor blades maintain an optimum tip speed ratio (TSR). As the wind turbine characteristics are nonlinear, a proper control system is needed to extract maximum power from wind (Mahmoud 2012), (Aryuanto 2011). For maximum power extraction, TSR control (Athanasios 2012), (Ali 2007) Perturbation and observation or hill climbing searching (Moor 2003), (Koutroulis 2006) and power signal feedback (PSF) (Raju 2004), (Azouz 2010), (Galdi 2011) technologies are available.

Most commercially available small wind turbines have permanent magnet generator. So the system does not consume reactive power from grid but wind turbine generation can be used to provide local reactive power consumption. It will minimize reactive power flow over the grid and thus minimizing the losses (Peiyuan 2010). In article (Peiyuan 2010), a stochastic optimization methodology has been introduced to control reactive power of wind turbines. There are several technologies available to provide the reactive power such as static var compensator (SVC), static synchronous compensator (STATCOM) (Saghaleini 2012) but all these technologies need extra equipment and costs.

Reactive power of wind turbine generation system depends on the inverter configuration. There are extensive researches concerning the reactive power control of the inverter. In (Bouafia 2009), a fuzzy logic controller has been used to control both active and 
reactive power. In (Cortes 2008), a predictive control method has been introduced to control both active and reactive power. A nonlinear sliding mode control system for power control of a three phase gridconnected inverter is discussed in (Jiabing 2011). A non linear decoupling method based reactive power control methodology is proposed for grid-connected PV inverter in (Cagnano 2011). A controlling strategy for Current Source Boost Inverter (CSBI) using phasor pulse-width-modulation (PPWM) is proposed and verified using simulation result in (Saghaleini 2011). Article (Saghaleini 2012) describes only the reactive power control with a CSBI using PPWM in details with both simulation results and experimental results. All the techniques are applied to grid-connected inverter. The inverter can be controlled to provide reactive power to the grid. In most cases, the techniques are applied and verified with a simple DC input to the inverter. A research should be performed on a small grid-connected wind turbine system along with inverter that can control reactive power flow. In this paper, a control system for control of reactive power along with maximum power point tracking (MPPT) operation has been developed for a small wind turbine.

\section{Some Issues of Small Wind Turbine}

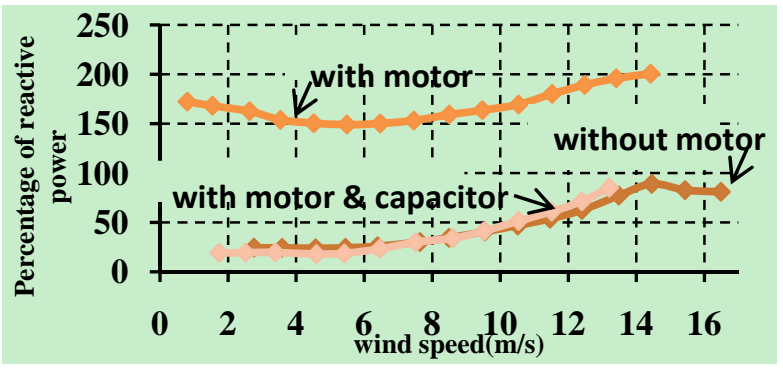

(a)

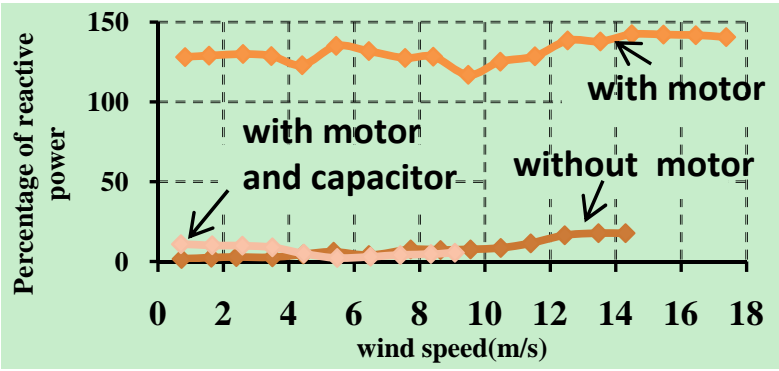

(b)

FIG. 1 (A) REACTIVE POWER FROM DRAWN FROM THE GRID FOR WIND TURBINE A, (B) REACTIVE POWER DRAWN FROM THE GRID FOR WIND TURBINE B [19].

Most of the commercial small wind turbines are in the range of 1-10 $\mathrm{kW}$. To investigate the power production characteristics under variable electrical loads, a bunch of experiments has been done and explained broadly in (Alimuzzaman 2012). From that recent article, it is clear that most of the commercial available small wind turbine cannot produce reactive power when required. Figure 1(a) below shows that the reactive power is drawn from the grid when an induction motor is connected between grid and turbine. Figure 1(b) below shows reactive power is drawn from the grid test results of another wind turbine. It is evident that when an induction motor is connected, all the reactive power comes from the grid and wind turbine inverter does not contribute. A local capacitor can help to compensate the required reactive power. However, a local capacitor can provide a fixed amount of reactive power not related to the load and such capacitors are costly. It would be ideal if a wind turbine inverter can provide the reactive power for the local load, which could be achieved by a modification to the inverter control as proposed below.

\section{Small Wind Turbine Configuration for This Research}

In this research, a small wind turbine system similar to a practical one has been considered. The system consists of wind turbine, permanent magnet generator, rectifier, DC-DC converter, inverter, transformer, grid and the control system. A block diagram of the system is presented below.

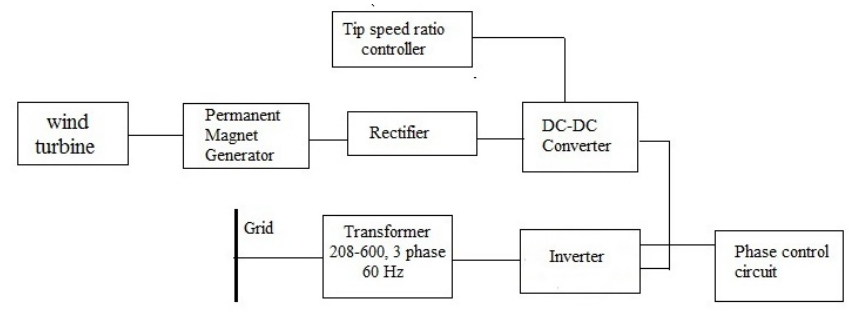

FIG. 2 BLOCK DIAGRAM OF A SMALL WIND TURBINE SYSTEM

\section{System Modeling}

The main parts of the system are wind turbine, permanent magnet generator and the power electronics.

Wind turbine: The wind turbine used in this study is a $1.1 \mathrm{~kW}$ system. The well-known equation of wind turbine power is

Where

$$
\mathrm{P}=.5 \rho A V^{3} \mathrm{C}_{\mathrm{p}}
$$

$$
\begin{aligned}
& C_{p}=f(\lambda) \\
& \lambda=\omega \frac{r}{v}
\end{aligned}
$$

Here $\mathrm{P}=$ Power(watt)

$\rho=\operatorname{air} \operatorname{density}\left(\mathrm{Kg} / \mathrm{m}^{3}\right)$,

$\mathrm{A}=$ rotor blade area $\left(\mathrm{m}^{2}\right)$, 
$\mathrm{V}=$ wind $\operatorname{speed}(\mathrm{m} / \mathrm{s})$,

$\mathrm{Cp}=$ Power Coefficient,

$\lambda=$ Tip speed ratio,

$\omega=$ rotor blade rotation $(\mathrm{rad} / \mathrm{s})$,

$\mathrm{r}=$ blade radius $=0.9 \mathrm{~m}$

For this particular wind turbine, a maximum value of $\mathrm{Cp}$ is assumed as 0.5 and it happens when tip speed ratio is six. Generally, Cp increases with the increment of tip speed ratio for variable speed wind turbine until $\mathrm{Cp}$ reaches its maximum value and after that it decreases with tip speed ratio increases (Ming-Fa 2012), (Putrus 2009), (Bhowmik 1998). The following equation (4) represents a typical $\mathrm{Cp}-\lambda$ characteristic where $C p$ is maximum (0.5) when $\lambda$ is equal to six. This equation is used to define the $\mathrm{Cp}-\lambda$ relation of this particular small wind turbine.

$$
C p=-0.014 \lambda^{2}+0.169 \lambda-0.002
$$

The wind turbine is configured with the equation (1), (2), (3) and (4).

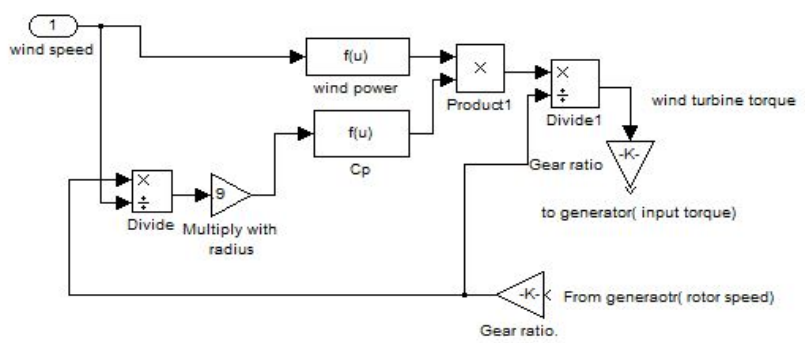

FIG. 3 WIND TURBINE MODEL

Permanent Magnet Generator: For this system, a permanent magnet synchronous generator has been used. The generator is $1.4 \mathrm{~kW}, 4$ pole machine.

The generator is modelled using the following equations (Damien 1997).

$$
\begin{gathered}
\frac{d}{d t} i_{d}=\frac{v_{d}}{L_{d}}-\frac{R}{L_{d}} i_{d}+\frac{L_{q}}{L_{d}} p \omega_{r} i_{q} \\
\frac{d}{d t} i_{q}=\frac{v_{q}}{L_{q}}-\frac{R}{L_{q}} i_{q}+\frac{L_{d}}{L_{q}} p \omega_{r} i_{d}-\frac{\lambda_{a} p \omega_{r}}{L_{q}} \\
T_{e}=1.5 p\left[\lambda_{a} i_{q}+\left(L_{d}-L_{q}\right) i_{d} i_{q}\right]
\end{gathered}
$$

Where, $\mathrm{L}_{\mathrm{q}}, \mathrm{Ld}=\mathrm{q}$ and $\mathrm{d}$ axis inductances

$\mathrm{R}=$ Resistance of the stator windings

$\mathrm{i}_{\mathrm{q}}, \mathrm{i}_{\mathrm{d}}=\mathrm{q}$ and $\mathrm{d}$ axis current

$\mathrm{V}_{\mathrm{q}}, \mathrm{V}_{\mathrm{d}}=\mathrm{q}$ and $\mathrm{d}$ axis voltage

$\omega_{\mathrm{r}}=$ angular velocity of the rotor

$\lambda_{\mathrm{a}}=$ Amplitude of the flux

$\mathrm{p}=$ pole pairs number

$\mathrm{T}_{\mathrm{e}}=$ Electromagnetic torque

Power electronics: The generator is connected to a rectifier as shown in Figure 2. The system output is two phase. The rectifier is connected to an inverter via a DC-DC boost converter. The inverter is connected to a transformer. The transformer rating is $1.5 \mathrm{kVA}(208 \mathrm{~V}$ to $600 \mathrm{~V}, 3$ phase).

A PI controller is used for the DC-DC boost converter switch control and a proportional controller is used for the phase control of the PWM inverter. Blocks from Simulink power system block-set are used to model the power electronics. Block parameters were adjusted accordingly. A full system model in Simulink is presented in Figure 4. The proposed control system is described in the following sections.

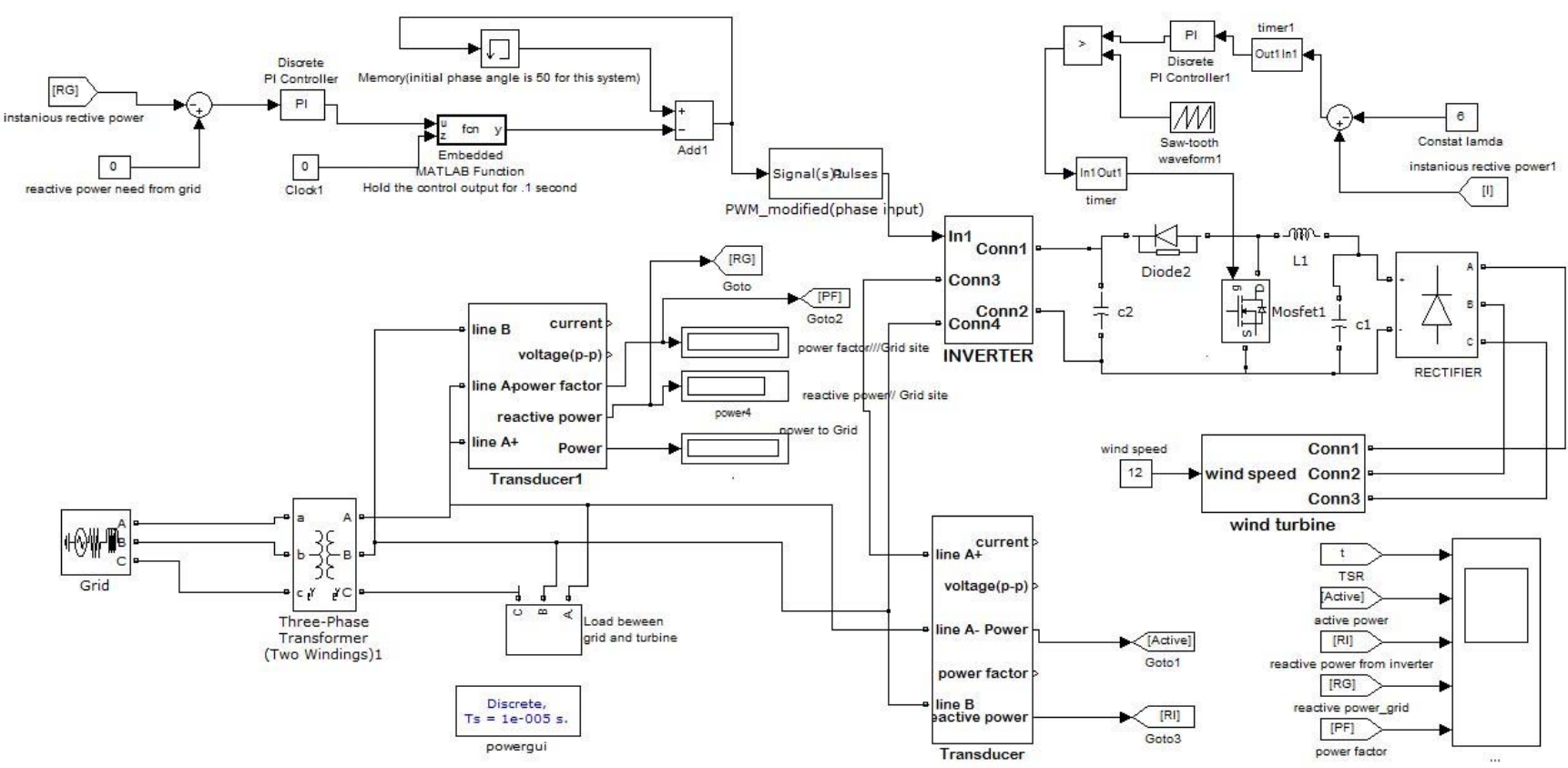

FIG. 4 SYSTEM MODELING IN SIMULINK 


\section{Control System Design}

In this system, there are two different control units and they are independent. Detailed description of these control systems are presented below.

\section{Active Power Control System}

To extract maximum power, the wind turbine has to rotate at a specific speed at a particular wind speed. When it passes through the air, the turbine blade creates turbulence and wake. If the subsequent blade arrives before the turbulence has vanished, it is not possible to extract maximum power from the wind but if the blade arrives just after the wake has vanished, it can extract more power. For any turbine, this effect can be assigned a constant number referred to as optimum TSR (Kooning 2012).

The power coefficient of a wind turbine is maximized when it rotates at the optimum tip speed ratio. The main objective of this active power control system is to maintain the tip speed ratio at its optimum value for any wind speed. In this research, a PI controller is used with the DC-DC boost converter. A speed sensor measures the rotational speed of the turbine and an anemometer measures wind speed, and the instantaneous TSR is calculated with these two values. The instantaneous TSR is compared with the optimum TSR, and thus the error is calculated. (see Figure 4) The PI is used to correct the error in TSR. The output signal of the PI controller is compared with a triangular wave and a gate signal is generated for the DC-DC boost converter switch and thus the DC current from the generator to load is controlled. As the generator rpm depends on its load, indirectly the generator rpm can be controlled to a desired value. Again, the generator and the turbine are mechanically coupled; therefore the turbine is controlled to run at its optimum TSR. Figure 5 is a flow chart of the controller. If instantaneous TSR is the same as the desired TSR, then the PWM duty ratio is not changed. If instantaneous TSR is more than the optimum TSR, then the PWM duty ratio is increased or otherwise decreased. The control code also keeps the duty ratio within a set limit. Therefore, the system active power is controlled by adjusting the DC input to the inverter. The designed controller also makes sure that the maximum power is extracted from the wind.

\section{Reactive Power Control System Design}

The PMG output for this system is a variable AC power that varies with the wind speed. The generator output is converted to DC power with a rectifier. The DC power goes through a DC-DC boost converter and is then converted to $60 \mathrm{~Hz}, 208 \mathrm{~V}$, AC power with an inverter. In this research, a four pulse two leg inverter is used. The inverter pulse width modulation (PWM) generator is carrier-based. It creates pulses by comparing a triangular carrier waveform with a reference modulating signal as shown in the Figure 6. In this research, the triangle carrier signal is compared with the sinusoidal modulating signal. As the inverter has two legs therefore four pulses are needed for four switches. The phase, frequency, and amplitude of the output voltage depend on the characteristics of the reference modulating signal. So by changing the modulating signal phase, the output voltage phase can be controlled (Saghaleini 2012).

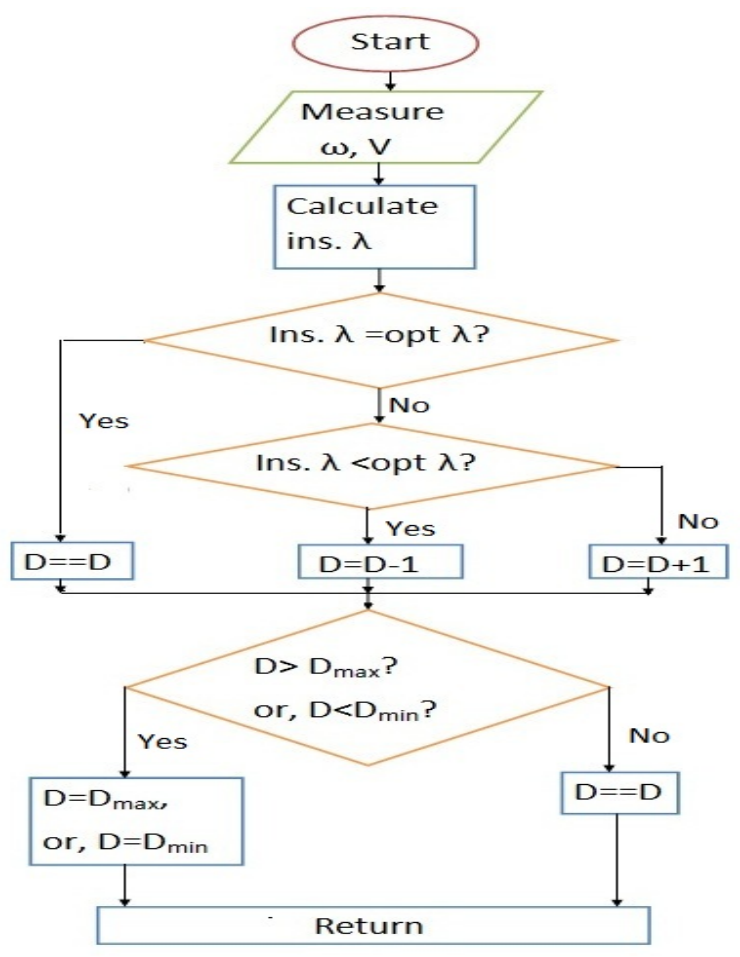

FIG. 5 FLOW CHART FOR ACTIVE POWER CONTROL

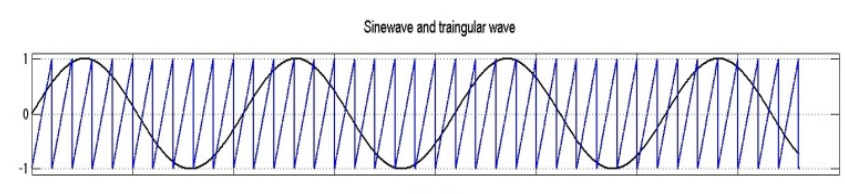

Pulse 1

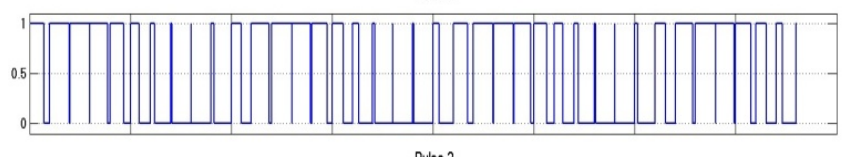

Pulse 2

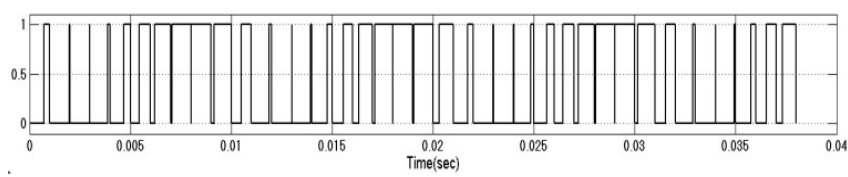

FIG. 6 REFERENCE SIGNAL, CARRIER SIGNAL AND GATE PULSE FOR PWM 
Here a proportional controller and a memory block are used to control the phase angle of the output voltage. Memory block is added to avoid loop error. The controller works on the basis of the reactive power error. Reactive power error is the difference between the reactive power needed by the local load and the reactive power produced by the inverter. The memory block remembers the phase angle value that has been used during the previous time step. The controller changes its output according to the error, and using the memory value it adjusts the phase angle of the PWM generator to make the error equal to zero. With this control system, the reactive power production of the wind turbine can be controlled and thus the total reactive power exchanges with the grid can be also controlled.

\section{System Simulation and Results}

After modeling in Simulink, the total system has been simulated for different wind speeds and load demands. Here the simulation has been divided into three parts. They are demonstrated below.

Case study 1: wind speed $=12.5 \mathrm{~m} / \mathrm{s}$, load=pure resistive load, simulation run time $=$ one second

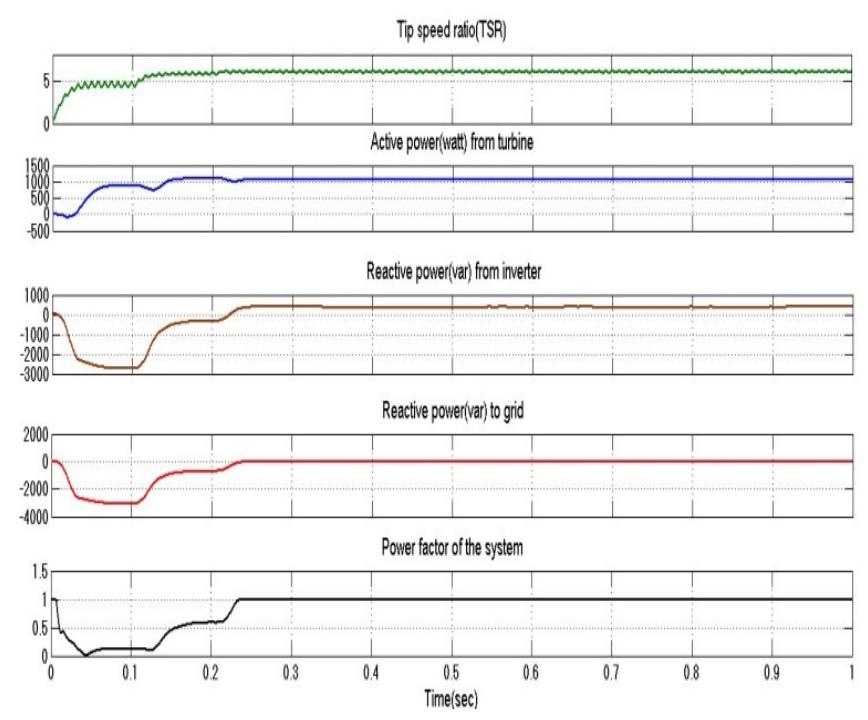

FIG. 7 CASE STUDY ONE

In Figure 7 it is shown that TSR is constant and its value is six. Though the load is purely resistive, the inverter produces small amount of reactive power, as there is a transformer in the system. But from the grid side transducer, it is clear that the total reactive power from the grid is equal to zero and for this reason the power factor is also very close to unity.

Case study 2: wind speed $=10 \mathrm{~m} / \mathrm{s}$, load=resistive and reactive load, simulation run time= one second
In this case( Figure 8), as the load is not purely resistive, the inverter produces reactive power to meet the load demand and thus reducing the reactive power from the grid to zero, and the grid side power factor remains close to unity.

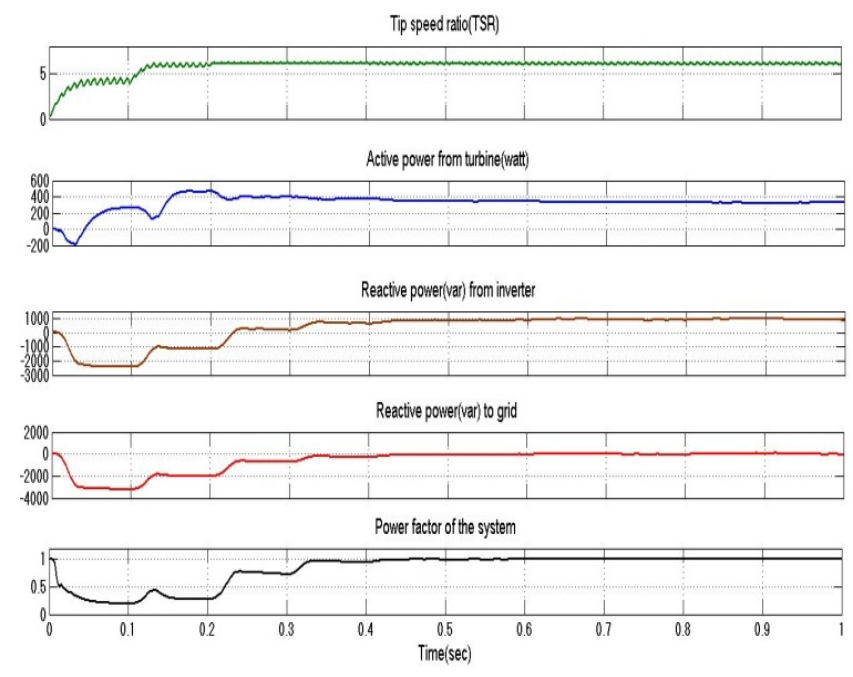

FIG. 8 CASE STUDY TWO

Case study 3: wind speed=variable, load=resistive and reactive load, simulation run time $=3.5$ second

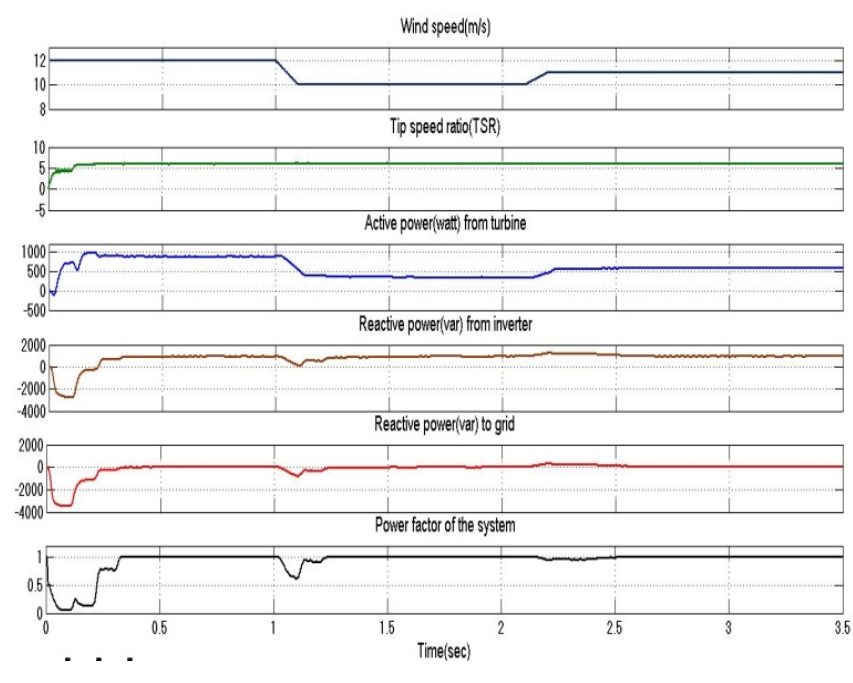

FIG. 9 CASE STUDY THREE

In this case (Figure 9), there are sudden changes of wind speed and the stability of the system has been verified. When wind speed changes from $12 \mathrm{~m} / \mathrm{s}$ to $10 \mathrm{~m} / \mathrm{s}$, the active power control circuit still maintains a TSR of six. Active power decreases as the wind speed decreases. However, as the load is not changed, the inverter produces the same amount of reactive power as before. Thus the total reactive power exchange with the grid is still zero, and the system maintains a power factor close to unity. Again, at $t=2$.1s when wind speed increase from $10 \mathrm{~m} / \mathrm{s}$ to $11 \mathrm{~m} / \mathrm{s}$, active power increases but TSR, reactive power, and the power factor remain unchanged. This indicates that the designed control 
system extracts maximum power from the wind and provides reactive power for the local load. This model and the designed controllers could be simulated for any set of input conditions.

\section{Conclusion}

In this research, a control system has been developed for a small wind turbine system that extracts maximum power from the wind, and ensures that the system and local load consume zero reactive power from the grid. The wind turbine inverter is controlled so that it produces the required reactive power needed by the local load. The proposed reactive power control system is less complicated, as it does not require any rotational reference or use d-q machine theory. A wind turbine system with this type of technology will provide or consume zero reactive power to or from the grid. Some grid distributors have included an extra charge for reactive power consumption. The proposed control system will avoid reactive power charge by not consuming reactive power from the grid.

\section{ACKNOWLEDGEMENTS}

The authors' would like to thank the Wind Energy Strategic Network, National Science and Engineering Research Council (NSERC), Canada for providing financial support for this research.

\section{REFERENCES}

Aryuanto Soetedjo, Abraham Lomi and Widodo Puji Mulayanto, "Modeling of Wind Energy System with MPPT Control", in International conference on Electrical Engineering and informatics(ICEEI), Bandung, 2011, pp. 1-6.

Athanasios Mesemanolis, Christos Mademlis, and Iordanis Kioskeridis, "A fuzzy-logic based control strategy for maximum efficiency of a Wind Energy Conversion System," in International Symposium on Power Electronics, Electrical Drives, Automation and Motion (SPEEDAM), Sorrento, 2012, pp. 7-12.

Ali M. Eltamaly, "Modeling of Wind Turbine Driving Permanent Magnet Generator with Maximum Power Point Tracking System," Journal of King Saud University, Engineering Science, vol. 19, pp. 223-237, 2007.

Azouz, M. Shaltout, A. Elshafei, M. A. Abdel-Rahim, N. Hagras, H. Zaher, M. and Ibrahim, M., "Fuzzy Logic Control of Wind Energy Systems," in Proceedings of the 14th International Middle East Power Systems Conference (MEPCON'10), Cairo University, Egypt, Cairo, 2010, pp. 935-940.

Alimuzzaman, Md. Iqbal, M.T. and Gerald Giroux, "An Investigation of Power Performance of Small Grid Connected Wind Turbines under Variable Electrical Loads" International Journal of Energy Science, Vol. 2, Iss. 6, pp. 282-289, December 2012.

BP Statistical Review of World Energy, June, 2012.

Bhowmik S. and Spee, R. "Wind speed estimation based variable speed wind power generation," in Proceedings of the 24th Annual Conference of the IEEE ,Industria Electronics Society, Aachen, 1998, pp. 596-601 vol.2.

Cultura, A. B. and Salameh, Z. M. "Modeling and Simulation of a Wind Turbine Generator System", Power and Energy Society General Meeting, 2011, IEEE, San Diego, CA, 2011, pp. 1-7.

Cagnano, A. Tuglie, E. D. Liserre, M. and Mastromauro, R. A. "Online Optimal Reactive Power Control Strategy of PV Inverters," IEEE Transactions on Industrial Electronics, vol. 58, no. 10, pp. 4549- 4558, Oct. 2011.

Mohamoud M. Hussein, Tomonbu Senjyu, Mohamed Orabi, Mohamed A.A. Wahab, Mohamed M. Hamada, "Simple Maximum Power Extraction Control for Permanent Magnet Synchronous Generator Based Wind Energy Conversion System", in Japan-Egypt conference on Electronics Communications and computers (JEC_ECC), Alexandria, 2012, pp. 194-199.

Moor, G. and Beukes, J. "Maximum Power Point Tracking methods for small scale Wind Turbines", in Proceedings of Southern African Telecommunication Networks and Applications Conference (SATNAC), 2003.

Koutroulis, E. and Kalaitzakis, K. "Design of a maximum power tracking system for wind-energy-conversion applications," IEEE Transactions on Industrial Electronics, vol. 53, no. 2, pp. 486-494, April 2006.

Raju, A.B. Fernandes, B. G. and Chatterjee, K. "A UPF power conditioner with maximum power point tracker for grid connected variable speed wind energy conversion system," in First International Conference on Power Electronics Systems and Applications, IEEE, Hong Kong, 2004., pp. 107-112.

Galdi, V. Piccolo, A. and Siano, P. "Designing an Adaptive Fuzzy Controller for Maximum Wind Energy 
Extraction," IEEE Transactions on Energy Conversion, vol. 23, no. 2, pp. 559- 569, June 2008.

Peiyuan Chen, Siano, P. Bak-Jensen, B. and Zhe Chen, "Stochastic Optimization of Wind Turbine Power Factor Using Stochastic Model of Wind Power," IEEE Transactions on Sustainable Energy, vol. 1, no. 1, pp. 1929, April 2010.

Saghaleini, M. and Mirafzal, B. "Reactive power control in three-phase grid-connected current source boost inverter," in Applied Power Electronics Conference and Exposition (APEC), Twenty-Seventh Annual IEEE, Orlando, FL, 2012, pp. 904-910.

Bouafia, A. Krim, F. and Gaubert, J. P. "Fuzzy-Logic-Based Switching State Selection for Direct Power Control of Three-Phase PWM Rectifier," IEEE Transactions on Industrial Electronics, vol. 56, no. 6, pp. 1984-1992, June 2009.

Cortes, P. Rodriguez, J. Antoniewicz, P. and Kazmierkowski, M. "Direct Power Control of an AFE Using Predictive Control," IEEE Transactions on Power Electronics, vol. 23, no. 5, pp. 2516-2523, Sept. 2008.

Jiabing Hu, Lei Shang, Yikang He, and Z.Z. Zhu, "Direct Active and Reactive Power Regulation of GridConnected DC/AC Converters Using Sliding Mode Control Approach," IEEE Transactions on Power
Electronics, vol. 26, no. 1, pp. 210-222, Jan. 2011.

Saghaleini, M. and Mirafzal, B. "Power control in threephase grid-connected current-source boost inverter," in IEEE Energy Conversion Congress and Exposition (ECCE), Phoenix, AZ, 2011, pp. 776-783.

Ming-Fa Tsai, Chung-Shi Tseng, and Yu-Hsiang Hung, "A novel MPPT control design for wind-turbine generation systems using neural network compensator," in IECON 2012 - 38th Annual Conference on IEEE Industrial Electronics Society,Montreal, QC, 2012, pp. 3521-3526.

Putrus, G. Narayana, M. Jovanovic, M. and Pak Sing Leung, "Maximum power point tracking for variable-speed fixed-pitch small wind turbines," in 20th International Conference and Exhibition on Electricity Distribution Part 1, Prague, Czech Republic, 2009, pp. 1- 4.

Damien Grenier, L.-A.Dessaint and Yva Bonnassieux, "Experimental Nonlinear Torque Control of a Permanent-Magnet Synchronous Motor Using Saliency," IEEE Transactions on Industrial Electronics, Vol. 44, No. 5, October, 1997.

Kooning, J. D. Meersman, B, Vandoorn, T. L. and Vandevelde, L. "Evaluation of the Maximum Power Point Tracking performance in small wind turbines," in Power and Energy Society General Meeting, IEEE, San Diego, CA, 2012, pp. 1-8. 